\title{
Algumas Considerações Sôbre o Direito Natural
}

\author{
ARNOLD WALD \\ (Advogado no Distrito Federal)
}

\begin{abstract}
$\mathrm{O}$
problema do direito natural ressurge sempre nas épocas de crise e de transformações scciais, quando o direito vigente deixa de corresponder às aspirações da elite. Quando as normas jurídicas não resolvem devidamente os conflitos surgidos, quando a estrutura econômica ou política da sociedade se modifica, apela-se para o direito natural a fim de manter certas garantias e de readaptar o direito às novas condições de vida. E' nas fases revolucionárias da história que o direito natural recebeu os seus maiores impulsos. Quando um direito se constitui, é relativamente adequado ao meio no qual será aplicado. A primeira fase de estudos jurídicos, é de exegese, de comentários à lei. Cum o decorrer do tempo e a criação de novos problemas na vida social, desenvolve-se o estudo dogmático e crítico. Ao lado do texto da lei, estudam-se as interpretações jurisprudenciais. A própria doutrina pasșa a ter papel ativo na construção jurídica. Renascem os estudos de história do direito, de direito romanc, de direito comparado, de filosofia do direito.
\end{abstract}

E' o que notamos na França, após a elabcração do Código Napoleão, quando BUGNET dizia ensinar não o direito civil mas tão somente o Código. E por sua vez Demolome intitulava o seu curso de direito civil - curso de Código Napoleão. E o velho tratado de BAUDRY-LACANTINERIE que dominou as faculdades francesas nas últimas décadas do século passado ainda explicava o código, artigo por artigo como 0 fazem ainda hoje os nossos comentários. Considerava-se então que a função do jurista era exclusivamente de interpretar o pensamento do legislador, cabendo ao juiz a missão de aplicar a lei. São homens como BAUdANT, BuFnorr, LABBÉ e posteriormente $\mathrm{S}_{\mathrm{A} \text { - }}$ LEILles, Josserand e Planiol que, diante das novas condições sociais, procuram vencer a escola da exegese. Recorrem então os juristas ao direito comparado e o congresso de Paris de 1900 é a certidão de nascimento do direito comparado como método jurídico assinada por SALEILLES, LAMBERT e LÉvYULlMAN. Caberia a SALEILles divulgar a técnica legislativa alemã ao estudar o Burgerliches Gesetzbuch (código civil alemão que entrou em vigor no dia $10^{\circ}$ de janeiro de 1900). LAMBERT dirigiu o Instituto de Direito Comparado de Lião, dedicando-se ao estudo do direito constitucional norte-americano e publicando Le gouvernement des juges e L'ancêtre américain du droit américain.

LÉvy-UlLman se consagra à analise do direito inglês. Pode-se caracterizar os diversos métodos empregados pelos comparatistas franceses por uma 
tendência comum no sentido de procurar os dados reais que constituem o denominador comum das diversas legislações. A finalidade dos estudos de direito comparado na época é no sentido da uniformização do direito, da pesquisa dos elementos comuns aos diversos direitos. E mesmo quando as formas são diversas, os juristas procuram apontar como, por técnicas especiais, os direitos afinal alcançam as mesmas finalidades. Este sentimento é tão vivo que estudando aquela fase do direito comparado, o Conselheiro MARC ANCEL assinalou a vocação universalista da doutrina comparativista francesa no início do século XX. E' interessante nctar que as próprias formulas empregadas revelam o intento dos estudiosos.

SAleilles almeja encontrar " $a$ direito comum da humanidade" enquanto EDOUARD LAMBERT se refere ao "direito comum legislativo" e LÉvy-ULLMAN ao "direito mondial do século $X X$ ".

Ao mesmo tempo, retornam os estudiosos ao direito antigo, ao direito romano e recebe novo incentivo o direito natural. A explicação é simples. Por longo tempo, as textos do Código Civil resolveram os problemas jurídicos com maior ou menor eficácia. A revolução industrial todavia transformou as bases da sociedade e coube à jurisprudência e à doutrina extrair do Código Napoleão teorias que nêle inexistiam por responderem a problemas inexistentes no momento da sua elaboração. Foi o milagre realizado pelos juizes e pelos juristas franceses que permitiu dar a elasticidade necessária ao Código $\mathrm{Na}$ poleão fazendo com que venha a comemorar o ano passado o seu $150^{\circ}$ aniversário. Mas já nos inicios do século XX não bastava o estudo artigo por artigo do código. Passara a época da pura exegese. RIPERT em prefácio à edição do tratado de PLANIOL assinala com muita acuidade a transformação sofrida pelos estudos jurídicos.

"Le droit civil n'avait été jusqu'alors que l'étude du Code, suivant Demolombe ou suivant Laurent, car il y avait plusieurs évangiles. Nous comprîmes tout à coup que c'était autre chose. C'est toute la vie, le conflit des intérêts privés, la lente formations des institutions civiles, l'affinement par la pratique des règles de conduite, les luttes d'autrefois terminées par le triomphe d'une règle les luttes d'aujourd'hui poursuivies devant les tribunaux, l'intervention incessante du législateur, l'action de la pratique judiciaire."

Na realidade, é uma revolução jurídica aquela que data do fim do século passado, provocada pela revclução industrial que a antecedera. Não é só o direito civil que abandona o método exegético com a substituição do tratado de Baudry-Lacantinerie pelo de Planiol e a publicação dos ensaios de FrançoIs GÉny sôbre os métodos de interpretação e a ciência e a técnica. Simultâneamente com o abandono do método exegético e a introdução dos estudos comparativistas, assistimos à volta aos estudos romanísticcs com a publicação do Traité de Droit Romain de GIRARD que sucede assim a AcCARIAS, e, por outro lado, vemos o renascimento do direito natural, apontado por Charmont e Saleilles.

Pode parecer estranha a volta ao direito natural no fim do século passa. do. Seria necessário lembrar a atmosfera intelectual então existente. Na realidade, o evolucionismo científico se impusera. Era a época dos cientistas. 
SPENCER liderava os fiiósofos. TAINe já dissera que a virtude e o vício eram produtos como o acúcar ou o vitríolo. AUGUSTo ComTe elaborara a lei dos' três estados mostrando que a metafísica tinha sido definitivamente sobrepujada. A era positiva começava: O historicismo alemão de Savigny e Puchta via no direito uma emanação do espírito popular (volksgeist) que se devia desenvolver espontâneamente como a língua e não sofrer a rigidez imutável dos códigos. A física sobrepujara a metafísica. Mas brevemente novas influências se fizeram sentir. O pragmatismo de William JAMES e a filosofia de BERGSON procuraram alcançar o que COMTE define como inacessível ao espírito humano. A intuição bergsoniana renovou a metafísica. Ac mesmo tempo, no campo do direito internacional, voltava-se a falar em direitos naturais. MANCINI elaborava o princípio das nacionalidades alegando o direito natural de auto-determinação de cada nação. A cada nação deveria corresponder, de acôrdo com o direito natural, um Estado.

Em profundo artigo, publicado na Revue Trimestrielle de Droit Civil em 1902 e intitulado Ecole historique et droit naturel, RAYMOND SALEILles assinala a importância do direito natural. Pareceria normal, escreve, que o direito natural tivesse desaparecido com a vitória da escola histórica sôbre a escola dogmática e filosófica. Numa época dominada pela técnica científica, o jurista apegado ao direito natural haveria de ser considerado como o fantasma de outro tempo, caindo no mesmo descrédito que os teólogos. O empirismo estava consolidado de tal modo que se expulsava do direito não só o direito natural mas todos os princípios e as construções jurídicas não radicadas na realidade da vida. Ao juiz caberia aplicar a lei sem indagar se é ou não justa. De acôrdo com a escola histórica, o próprio legislador apenas aparentemente era o criador da lei. Esta brotava espontâneamente. O legislador apenas dava forma às normas que a evolução histórica impunha. "Le droit naturel étais expulsé, jusqu'á ses dernières consèquences, aux trois degrés de la fonction juridique: législative, scientifique et judiciaire. On se saurait imaginer déroute plus complète." Mas, como Fenix, a teoria do direito natural ressurgiu das suas próprias cinzas. Já SALEILles, numa época de triunfo incontestável do positivismo que nega a existência de qualquer direito não elaborado pelo Estado, procura apontar os primeiros sintomas da "revanche" do direito natural, afirmando que existe um problema do direito e que êste problema comporta um certo idealismo. "L'attaque avait été vie. De l'excès où elle sétait laissé entraîner devait sortir, ici comme ailleurs, une réaction forcée. Ce sont ces premiers symptômes que je voudrais signaler".

Oito anos depois, em 1910, Chermont publicava a sua obra "La Renaissance du Droit Náturel". Assinalava no prefácio a importância histórica incontestável do direito natural e o seu papel no campo do direito penal e do direito internacional público, considerando os princípios do direito das gentes como emanados do direito natural já que não consolidados legislativamente. Referia-se ainda ao caso Dreyfus recentemente debatido mostrando que era essencialmente um problema de direito natural. "Et, cepandant, ce qui s'agitatt dans ce débat, escreve, c'est une question de droit natural - primordial à la vérité - celle de savoir si le droit d'une seule personne peut tenir en échec les intérêts, la vie d'un pays tout entier". 
Já vitorioso 0 positivismo receiava ter ido longe demais. E voltava a apelar para o direito natural. Que acontecerá?

Na realidade, os positivistas puros como Duguit e KELSEN quiseram se libertar definitivamente da metafísica do direito natural. Não há direito natural, dizia, há teorias do direito natural. Devia o direito pasitivo prescindir definitivamente da base metafísica. Direito era tão sòmente o direito positivo. O direito elaborado pelos órgãos competentes na forma determinada pela constituição. HANS KELSEN ao distinguir entre o campo do Ser (Sein) e do Dever Ser (Sollen) inclui as normas jurídicas entre as normativas, distinguindo-as das regras morais e religiosas. O direito se distingue da justiça que é um conceito subjetivo em que cada um condensa os seus desejos, as suas aspirações. O direito é um conjunto de normas concatenadas, oriundas umas das: outras, constituindo a pirâmide do direito puro. A norma fundamental seria o dever de obedecer ao legislador. O Estado também seria o conjunto das. normas jurídicas, confundindo-se pois com o direito. E' um sistema organizado, perfeito, sólido. Mas dos própricus positivista veiu a crítica. Se o direito público só existe quando a autoridade do Estado encontra limites, como poderão ser confundidos o Estado e o Direito? Se o direito limita o Estado, como identificar ambos, pergunta Duguit. O problema é de solução difícil. Merecem transcrição as palavras do decano de Bordeus que foi c inimigo mais veemente da metafísica. Dizia LÉon Duguit apontando as falhas da teoria do direito puro que:

"Si l'on identifie l'Etat et le Droit, comme le fait KeLSEN, il parait bien difficile d'établir une limitation de l'État par le Droit et en effet je n'en ai pas trouvé de trace dans l'oeuvre considérable de Kelsen. Plus j'avance en. âge et plus je reste convaincu que toutes les spéculations juridiques sont vaines si elles n'arrivent pas à déterminer d'une façon positive le fondement solide d'une limitation juridique appcrtée à l'action de ceux qui dans une société donnée individus, groupements, classes sociales, détiennent la plus grande force."

A crítica feita por Duguit vale não só para a teoria de KELSEN como para todo o positivismo. Sem o direito natural, como será possível limitar a autcridade do Estado?

O próprio Dugurt teve dificuldade em resolver a questão. Mas, inimigo da metafísica, recorreu aos direitos naturais do indivíduo consolidados pela Declaração de 1789 . E no seu tratado declara estarem vigentes os princípios de 1789 e afirma que na doutrina individualista que ainda está na base do nosso direito positivo, a fôrça obrigatória da lei deriva mais da sua conformidade com êsses princípios do que da vontade nacional.

KELSEN, ficando no direito puro, teve dificuldades para garantir certos direitos inerentes ao homem que todavia eram estranhos à técnica jurídica . Assim, reconhece o direito puro, fazendo abstração dêsses direitos. Mas, diz o desembargador OSCAR TENóRIO, como KANT após escrever a crítica da razão pura estudou a razão prática, KELSEN, ao lado da teoria geral do direito puro, escreveu a sua obra sôbre a democracia que ccrresponde à razão prática. 
De fato, destruído o baluarte dos direitos e garantias individuais, abandonado o padrão moral, o que resistirá ao arbítrio dos governantes? Não devemos esquecer que, após têrmos passado do absoluto ao relativo, devemos agora passar das certezas à negação sem perder todo valor moral, na palavra de BARRÈs.

Já tivemos a ocasião de dizer a êste respeito que a moral tradicional, as. idéias religiosas, o direito natural foram abandonados. Como todavia manter um limite à atividade do Estado? Só há direito público quando os poderes: sofrem certas restrições. O direito surgiu quando desapareceu o arbítrio. Como manter a existência do direito público? Como limitar a vontade du Estado, após ter vista o fracasso da teoria da auto-limitação de JELlinEK? E' preciso defender a existência do direito público. E para atingir tal fim somos obrigados a evocar noções metafísicas. Por que o homem e o Estado. deverão obedecer a normas de direito interno ou de direito internacional que são contrários aos seus interêsses desde que não estejam forçados a fazê-lo? Eis o problema que JEAN JACQUES ROUSSEAU não soube resolver e que ainda hoje preocupa os internacionalistas como GeORges ScELle. Aceitando o dogmatismo jurídico, assim mesmo deveremos recorrer à metafísica para proteger os direitos do homem contra a onipotência estatal. Na verdade, à metafísica, aplica-se a frase de Horácio, em relação à natureza "Naturam expelles furca, tamen usque recurret".

SAleilles, Le Fur e GÉny já falaram em direito natural. E o direito. natural vem a ser como a moral leiga que os homens que abandonaram a religião e que não querem aceitar o reino da fôrça são obrigados a admitir. "Diz RIPERT: "Ils ne croient plus au droit naturel mais ne veulent pas de l'arbitraire du droit positif. Alors bien plus fidèles qu'ils ne le croient aux enseignements de l'École Historique ils considèrent qu'il y a dans toutes les sociétés une évolution que le droit doit se borner à consacrer." Os néotomistás se baseiam, com JACQUES MARITAIN à frente, no ideal do bem comum. GaSTON MORIN defende o personalismo. E mesmo aqueles que se rebelam contra a metafísica e desconhecem o direito natural mas se revoltam contra o arbitrário, contra o reino da fôrça ou do número, mesmo aquêles criam um direito novo para orientar e fiscalizar o direito positivo. Assim é que DUGUit fala no direito objetivo baseado na solidariedade social, DABIN alude ao direito natural moral e GuRvirch ao direito intuitivo. O próprio RIPERT é um jusnaturalista "malgré lui" como o assevera Vicente Rao. E' preciso esta noção para manter a dignidade do homem e um mínimo de direito do homem no momento de crise que o Brasil e o mundo atravessam. Crise brasileira ainda recentemente diagnosticada por SAN TIAGo DANTAS em excelente conferência em que aponta a decadência da classe dirigente. Crise em que novamente hão os estudiosos de recorrer ao direito natural, ao direito comparado, à história do direito a fim de concorrer para o restabelecimento de um equilíbrio rompido. 